
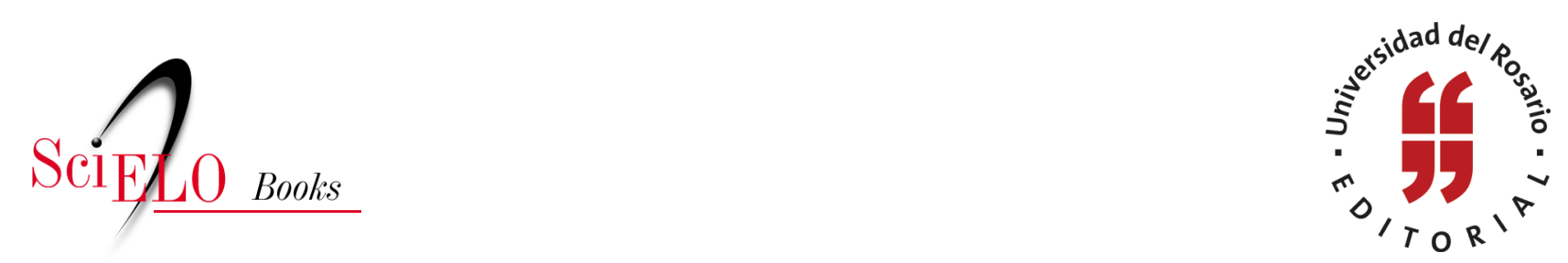

\title{
Capítulo III \\ Los usos de la tierra en Pueblo Viejo: un mismo suelo, aprovechamientos distintos
}

\author{
Felipe Rojas Arias
}

\section{SciELO Books / SciELO Livros / SciELO Libros}

ROJAS ARIAS, F. Los usos de la tierra en Pueblo Viejo: un mismo suelo, aprovechamientos distintos. In: Ayer mineros, hoy ecoguías y concesionarios: tensiones en torno a la conservación ambiental, el uso de la tierra y el trabajo en Guasca, Cundinamarca [online]. Bogotá: Editorial Universidad del Rosario, 2015, pp. 131-181. Opera prima collection. ISBN: 978-958-738-589-2.

https://doi.org/10.7476/9789587385892.0004.

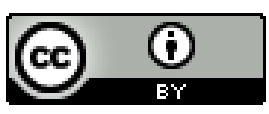

All the contents of this work, except where otherwise noted, is licensed under a Creative Commons Attribution 4.0 International license.

Todo o conteúdo deste trabalho, exceto quando houver ressalva, é publicado sob a licença Creative Commons Atribição 4.0.

Todo el contenido de esta obra, excepto donde se indique lo contrario, está bajo licencia de la licencia $\underline{\text { Creative }}$ Commons Reconocimento 4.0 . 


\section{Capítulo III \\ Los usos de la tierra en Pueblo Viejo: un mismo suelo, aprovechamientos distintos}

En este capítulo se analizarán los usos de la tierra propuestos y practicados por los habitantes locales y por la FNC, y las tensiones que se derivan de estos aprovechamientos. Este apartado se desarrolla a partir de las discusiones analíticas sobre las formas de manejo de los recursos naturales, las tensiones por el uso de recursos en áreas protegidas y las disputas entre los conocimientos locales y los conocimientos científicos de manejo ambiental.

A partir de las tensiones por el uso de la tierra, se discutirán los modelos de participación y manejo de las áreas protegidas. En general, los vecinos del sector tienen reparos sobre algunas de las formas en que la FNC está usando la tierra al interior de la RBE. Sin embargo, su inconformidad con el manejo de la RBE se manifiesta en críticas que se basan en las maneras como los vecinos entienden los usos de la tierra y sus beneficios. En primer lugar, se presenta una caracterización de los usos de la tierra en Pueblo Viejo y, luego, se exponen y analizan las tensiones, los acuerdos y los desacuerdos frente a su aprovechamiento. Finalmente, se presentan las propuestas de los pobladores frente al uso de la tierra en la RBE. 


\section{Los usos locales de la tierra}

Acorde con la figura 7, los usos de los recursos naturales que hacen las familias cuyas tierras están localizadas en las inmediaciones de la RBE son en su mayoría pecuarios. Estos consisten, en mayor proporción, en bovinos para producción lechera y, en menor medida, en ovinos. De las 14 familias que usan la tierra para el pastoreo de ovinos lecheros, cerca de 10 lo hacen para la venta y el autoconsumo, 3 venden sus pastos para esta actividad y una familia pastorea una vaca lechera para autoconsumo. Las familias del sector dependen en buena medida de la ganadería lechera porque esta actividad representa una de las principales fuentes de ingresos a partir de su venta a intermediarios que comercian con las pasteurizadoras. Como se muestra en la figura 4 del capítulo II, este tipo de ganadería es la principal actividad laboral de la localidad. Este aprovechamiento supone unos usos particulares de la tierra, como el pastoreo extensivo, el cuidado de las pasturas y potreros, entre otros, y unas relaciones económicas, como la venta de pastos entre los vecinos del sector.

La ganadería lechera requiere principalmente de buenos pastos y amplias zonas para pastar; entre más cercanos esos pastos a la vivienda del propietario del ganado mejor, debido a que se disminuye el tiempo y esfuerzo en el desplazamiento para efectuar el ordeño y el trasporte de las cantinas con la leche hasta su hogar, en donde, por lo general, los intermediarios recogen el producto. 
Figura 7. Usos de la tierra en Pueblo Viejo

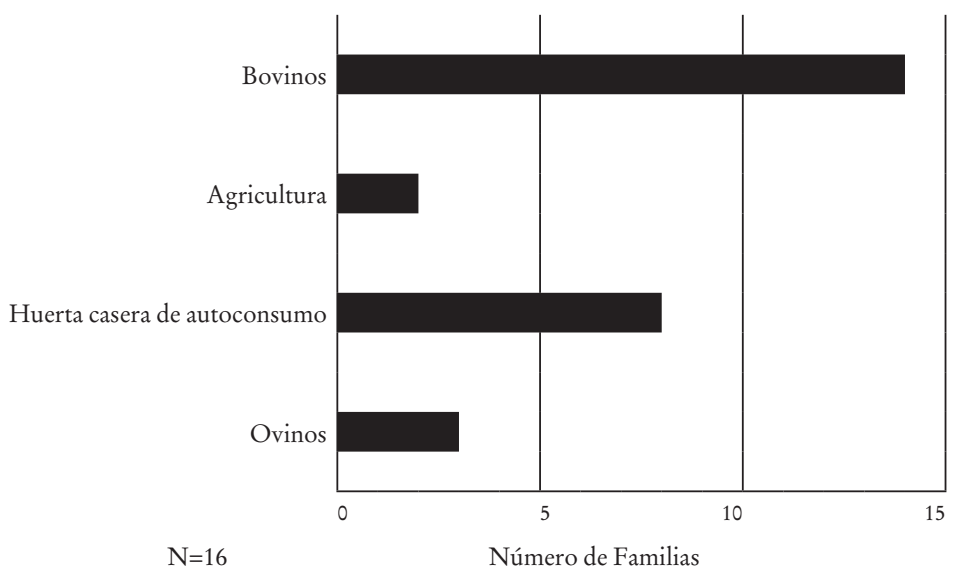

Fuente: elaboración propia.

En esta actividad los pastos se compran en una unidad de medida denominada "pastada", que equivale al tamaño del potrero. Entre más grande sea el potrero, mayor extensión para pastoreo y, por consiguiente, mayor el valor de la pastada. La altura del pasto en el potrero no influye en el valor de la pastada porque este se compra solo cuando ha alcanzado el crecimiento necesario para pastoreo lechero; si es muy bajo o muy alto no se compra porque disminuye la producción de leche. Por consiguiente, esta unidad de medida local equivale al desyerbe que hace el ganado de todo un potrero en un tiempo determinado. Una vez esto sucede, el propietario de las vacas paga al dueño del potrero el valor que hayan acordado por la pastada.

Por lo general, los ganaderos y vendedores de pasto tienen un cálculo aproximado del tiempo de desyerbe, aunque no se vende por tiempo, sino por cantidad de pasto. 
Vender pasto es diferente a un contrato de arrendamiento. La persona que compra los pastos no puede efectuar mejoras sobre los predios, simplemente introduce su ganado por un tiempo determinado y paga lo acordado al dueño del potrero. En este intercambio de un bien (el pasto), el comprador no tiene más derechos sobre el predio que el usufructo del agua y sus pastos.

Los propietarios de los predios se deben encargar, entonces, de mantener unos buenos pastos para la venta porque estos representan para ellos un cultivo que venden a los ganaderos. Sin embargo, hay casos en los que el ganadero controla plagas y abona para mejorar el pasto durante el tiempo que pasta su ganado en un determinado predio. El que compra el pasto tiene derecho a alimentar a su ganado hasta que se agote todo el corte. Con todo, es común que se calcule, de acuerdo con la cantidad de ganado y el tamaño del potrero, el tiempo que demorará en agotar el corte (desyerbe total). Adicional al pasto y al agua, la ganadería lechera requiere que las vacas tengan acceso a medicamentos, sal y concentrados, así como la aplicación de abonos y el control de plagas en los pastos.

Otro uso de la tierra en esta región consiste en las huertas de autoconsumo, cultivos, en su mayoría hortícolas, sembrados en pequeños terrenos cercanos a la casa de cada familia. Algunas de estas huertas de autoconsumo son cuidadas y cultivadas por cada familia o en compañía con otros familiares habitantes del sector. En este tipo de huertas sembradas en compañía no median relaciones monetarias sobre el intercambio de productos. 
En el trabajo de campo se constató que en algunos casos las semillas, las tierras, el trabajo y los insumos necesarios para cuidar la huerta eran aportados por parientes que cultivan en conjunto para obtener productos de autoconsumo, lo que deja ver formas no capitalistas de comercio. En consecuencia, la huerta casera no se destina para el mercado, aunque entra en circuitos de intercambio no sometidos a precios ni valores monetarios, sino que son mediados por las relaciones de parentesco de las personas que la siembran. Una vez se cosechan los productos, se reparten entre los miembros de la compañía sin que medien relaciones de tipo monetario.

Las huertas de autoconsumo utilizan un bajo porcentaje de productos químicos para abonar, proteger y fertilizar las cementeras, pues al no ser para la venta, no están mediadas por intereses de incrementar su productividad, tamaño y ganancias. Además, como son de autoconsumo, no existe la posibilidad de recuperar lo invertido en agroquímicos. Los productos que se siembran en este tipo de cultivos son hortícolas: predominan las habas, la cebolla en rama y el repollo. Sin embargo, la papa es otro producto que no escasea en las huertas caseras de Pueblo Viejo. Algunas familias también usan la huerta para sembrar hierbas aromáticas como el toronjil, la caléndula, la ruda, la limonaria, entre otras, y plantas ornamentales como las astromelias.

En Pueblo Viejo la agricultura como actividad económica es muy escasa por la falta de tierras, no solo por su aptitud, sino por el uso que le dan sus propietarios. En la época en que funcionaba la mina, la compañía explotadora de cal tenía 
algunos cultivos de papa y trigo destinados al comercio y el autoconsumo local trabajados por obreros de la empresa. En la actualidad, el único cultivo comercial de papa que hay no es sembrado por las familias del sector, sino por un arrendatario de fuera de Pueblo Viejo.

Hoy en día existe la RBE en las mismas tierras donde la compañía explotadora de cal practicaba la minería y algunas actividades agropecuarias, y que posteriormente (entre 1992, cierre de la mina, y 2007, constitución de la RBE) fueron aprovechadas por un arrendatario del señor Hoeck en ganadería y agricultura. En la reserva no arriendan los potreros ni permiten el desarrollo de actividades agrícolas de tipo comercial. La FNC está desarrollando en una pequeña porción de la RBE un banco de biodiversidad de papa y tiene junto al centro de visitantes una huerta orgánica de hortalizas. El resto de sus tierras están dedicadas a los procesos de restauración ecológica, ecoturismo, conservación del bosque y venta de pastadas.

\section{Tensiones por el uso de la tierra en la Reserva Biológica Encenillo}

Las poblaciones aledañas a las áreas de conservación formalmente establecidas ven restringidos el acceso y el uso de los recursos que en ellas se encuentran (Pinilla, 2004). Acerca de los parques nacionales en Sudamérica, Amend y Amend (1992, p. 463) sostienen que sus principales fuentes de problemas son los "conflictos con la población por actividades agropecuarias, ocupaciones ilegales y utilización de recursos del área protegida”. Algunos otros autores definen el 
problema en términos de la tensión entre la protección de los recursos naturales y su uso para la subsistencia humana (Villa, 1992), y la autonomía en el manejo de sus territorios y sus recursos (Pinilla, 2004; Peluso, 2005). Por ejemplo, existen casos como los del parque nacional Amboró en Bolivia, en donde se delimitaron áreas exclusivas de conservación, o de línea roja, en las cuales se restringían todo tipo actividades de explotación y producción para las poblaciones locales, lo cual implicó la racionalización de las actividades desarrolladas por los habitantes del parque (Moscoso, 1992).

En el caso de la RBE, la principal tensión que se presenta entre la FNC y los pobladores locales radica en las percepciones distintas frente al uso de la tierra en actividades agropecuarias y conservacionistas. En este sentido, se propone un análisis antropológico, cuyo interés es el estudio etnográfico de las formas de representación de los recursos naturales y cómo ello, en medio de procesos políticos, media en su aprovechamiento y genera tensiones.

La FNC ha permitido a la población local el uso de estas tierras para la ganadería. Antes de su constitución, el arrendatario del señor Hoeck no vendía pastaje y subarrendaba muy poca de la tierra que tenía en arriendo, pues él era quien utilizaba los potreros para su propio hato y agricultura:

Felipe Rojas: ¿Y de pronto cuando don Pedro ${ }^{14}$ administraba eso había más trabajo que actualmente?

14 Nombre cambiado. 
-Habitante local: Mmm, pues no, no y menos la gente podía vivir porque no había los arriendos como los hay ahorita. Ahoritica cuando cogió la Fundación eso pues sí tienen a la gente ahí, les han arrendado [vendido pasto] a cada uno dos, tres porteritos para que mantengan sus tres, cuatro vaquitas. Y antes no lo había porque cuando estaba don Pedro como administrador esto no dejaba, a nadie le vendía una pastada para nada. Sí.

-FR: ¿Y él entonces cómo hacía?

-HL: No, él solo mantenía todo, solo mantenía él.

-FR: De él, su ganado y su...

-HL: Sí él, todo, eso no dejaba mantener a nadie, a nadie nos vendía [pasto] decir "deme pastaje para una res, para unos dos meses”, no, nunca lo hizo. En cambio ahorita cambió mucho porque la persona que está hecho a cargo a eso [a las tierras de la RBE] está vendiendo los pastos, les deja para la mantención de sus tres, cuatro vaquitas que tiene la gente por ahí. (Entrevista a habitante local, 20 de agosto de 2012)

La RBE comprende aproximadamente unas 60 hectáreas de potreros y unas 135 hectáreas de bosque primario y secundario (FNC, 2008a). Actualmente, estas hectáreas de potreros están siendo utilizadas para restauración ecológica y ganadería extensiva. La FNC vende a un buen número de pobladores locales pastadas para el pastoreo de su ganado lechero. Esta ganadería, si bien es extensiva, implica el levantamiento de cercos que impiden el paso del ganado hacia el bosque y las fuentes hídricas. Por su parte, Corpoguavio, (Corporación 
autónoma regional del Guavio) ${ }^{15}$ como autoridad ambiental, ha exhortado por medio de sus visitas a la población local sobre el manejo cuidadoso de las fuentes hídricas para ganadería, es decir, para evitar que el ganado paste cerca de ellas, pues compacta el suelo con sus cascos y contamina las fuentes acuíferas.

En este sentido, la FNC ha hecho una apuesta por brindar a la población local opciones para el desarrollo de sus actividades ganaderas. No ha descartado del todo este tipo de prácticas, aunque pretende que se desarrollen de manera controlada para evitar daños ambientales:

-Felipe Rojas: ¿Bueno y entonces, en ese sentido las actividades que ahora se desarrollan a nivel productivo ahí [en la $\mathrm{RBE}$ ], la principal que yo he hecho en mis observaciones es la ganadería? [Carlos Castillo: correcto]. ¿En qué consiste esa ganadería, es tipo silvopastoril o de qué tipo es?

-CC: Digamos que es predominantemente extensiva, digamos si lo miramos desde el punto de vista cuantitativo. A lo que se quiere llegar, ese es el proceso en el que estamos trabajando, es a que integralmente se le dé un manejo sostenible donde, dentro del manejo sostenible, caben los sistemas silvopastoriles, pero caben otras cosas: es el adecuado manejo del recurso hídrico, un control de plagas evitando el uso de moléculas sintéticas que causen contaminación y

15 La relación entre Corpoguavio y la FNC tiene que ver con el apoyo que la Corporación brinda a la FNC en cuanto a la restauración ecológica. Hasta donde se averiguó en campo, Corpoguavio ha pagado la siembra y el mantenimiento de árboles al interior de la RBE. 
depredación. En fin, es todo un cambio en el cual estamos, digamos, como enfocados y es un proceso al cual estamos dando como comienzo. O sea no es un proceso que esté ya establecido, pero conceptualmente sí tenemos claro qué es lo que queremos hacer en esa dirección. O sea que digamos que la visión de las áreas productivas a mediano plazo, digamos dos, tres años es que se esté manejando de manera sostenible. Es decir minimizando el uso de agroquímicos, las pasturas que sean productivas, que estén generando el propósito productivo de una manera rentable para quienes lo están ejerciendo, sea como productores de leche o productores de carne, y de una manera que no comprometa negativamente, o impacte negativamente el recurso agua, el recurso suelo principalmente. (Entrevista a Carlos Castillo, jefe de la RBE, 18 de enero de 2013)

En la RBE sus funcionarios están tratando de articular algunas de las prácticas de uso de la tierra a nivel local con los usos de la conservación, lo que sugiere modificaciones en ambos sentidos. Tanto las formas productivas locales son modificadas como las ideas del conservacionismo estricto excluido de actividades agropecuarias. Esto quiere decir, en pocas palabras, la conservación de ciertos sistemas productivos propios de esta región, pero modificados según unos criterios particulares de sostenibilidad y, a la vez, la transformación de los paradigmas de conservación ambiental a la luz de las formas locales de producción. Discursos globales ambientales toman lugar en escenarios como Pueblo Viejo $\mathrm{y}$, a partir de procesos políticos, económicos y culturales a 
nivel local, dan pie para trasformaciones en las formas locales de aprovechamiento de la tierra, negociaciones, disputas y cambios en los mismos discursos ambientales.

La articulación de los usos locales y los conservacionistas que se ha dado hasta el momento en la RBE ha consistido en las concesiones de aprovechamiento pecuario de la tierra, que no han introducido mayores cambios en la ganadería, a excepción de la mengua de los pastos debido a los procesos de restauración ecológica y la delimitación de las zonas de pastaje para evitar daños a las fuentes hídricas. Por su parte, los paradigmas de la conservación se han modificado, en tanto, en la RBE se incluyen actividades pecuarias. No solo se trata, entonces, de un cambio en una sola dirección, pues de la negociación entre usos de los recursos naturales locales y los usos de la conservación ambiental devienen modificaciones en ambas formas de aprovechamiento.

Desde una perspectiva de manejo participativo de los recursos naturales (CBNRM), se propone articular los usos "tradicionales" con los conservacionistas. Con todo, una de las principales críticas a este modelo ha sido la construcción de lo que es "tradicional”. No se privilegian sino unos aspectos que son útiles al conservacionismo o que se ajustan al СBNRM y se pasan por alto otras formas de uso y conocimiento. Además, aquellos actores que aplican el modelo son los que gozan del poder para construir las ideas de lo "tradicional" desde posiciones esenciales y antagónicas: en algunos casos, lo tradicional es visto como ecológico y en otras como depredador y destructor. Así, se elaboran imágenes preconcebidas sobre lo local que muchas veces imposibilitan un diálogo 
con los conocimientos y las prácticas de las comunidades. El asunto se agrava cuando la población es considerada étnica o no. Para el caso de Guasca, su condición de campesinos es un factor que juega en contra, pues en las políticas multiculturales se excluye al campesinado. Ante la pregunta por las estrategias de inclusión de la población local en el plan de manejo de la reserva, el jefe de la RBE respondió:

Entonces digamos que hay segmentos de población, están digamos en una línea los arrendatarios [concesionarios], entonces con ellos estamos en un proceso de interacción que nos conduzca a que se adopten las prácticas de producción sostenible. Está la población infantil que se quiere persuadir al Colegio del Carmen y todo esto a que en sus programas de ciencias y en sus PRAE (Propuestas ambientales educativas), que haya cada vez mayor acercamiento de la población infantil, juvenil, hacia lo que ofrece la reserva, hacia el potencial de educación ambiental que ofrece la reserva. También para generar digamos apropiación de la población. Que sientan que eso no es que es una reserva allí, sino que es una reserva, nuestra reserva, que esto tiene una importancia y un impacto para la región, para sus propias vidas. Porque en la medida en que allá se esté conservando, en la medida en que ya se esté produciendo agua, pues ellos que viven ahí abajo, pues van a poder disfrutar y satisfacer sus necesidades básicas de una manera, digamos, adecuada. (Entrevista a Carlos Castillo, jefe de la RBE, 18 de enero de 2013. Cursivas del autor) 
Esta cita sugiere parte de la idea que la FNC tiene sobre la participación ambiental local. Como lo expone el jefe de la RBE, en el fragmento citado, la concesión sobre el uso de recursos naturales puede ser un mecanismo para fomentar la participación en el manejo de esta área protegida. No obstante, es muy interesante la forma en la que se entiende la participación, pues no solo se habla del trabajo, sino también de la educación ambiental y apropiación de la RBE por parte de la población. Para el jefe de la RBE, la inclusión de los habitantes se relaciona con interacciones en las que la FNC eduque ambientalmente a estas poblaciones a favor de los intereses de conservación de la FNC. Es una inclusión en la que los pobladores son sujetos que requieren ser intervenidos y concientizados en sus prácticas y formas de pensar, mas no entendidos como individuos que pueden aportar con sus conocimientos, intereses y necesidades al manejo de la RBE.

En el desarrollo de la entrevista, se le preguntó al jefe de la RBE si era posible que se dieran espacios de diálogo con la población local para que expresaran sus propuestas e inquietudes frente a la RBE, a lo que respondió que efectivamente estos se darían en el corto plazo. Con todo, estos espacios son entendidos por el jefe de la RBE como interacciones que permitan generar cambios en las formas de uso de los recursos ambientales locales, es decir, sin tener en cuenta lo que podría aportar la población, sino asumiendo que sus prácticas deben ser modificadas. Este proceso educativo, además, conduciría a que la población "entendiera" la importancia de la reserva para sus vidas, es decir, que se "apropiara de ella" como 
espacio que le presta servicios ambientales, mas no como territorio en el que tiene capacidad de decisión.

Por el momento, gran parte de la apropiación que la población ha hecho de la RBE ha sido a través de las concesiones. Si bien la venta de pastadas a la población no consiste en brindar empleos de manera directa, como se discutió en el capítulo anterior, sí implica que las personas puedan desenvolverse en una actividad laboral que les representa ingresos y uso de los recursos naturales de la reserva. Existe una relación directamente proporcional entre venta de pastos, empleo e ingresos. Siendo la ganadería la principal actividad laboral del sector, la población local depende de la venta de pastos para sustentar su economía. A mayor venta de pastos, mayores posibilidades de empleo en ganadería e ingresos para las familias de Pueblo Viejo.

Por esta razón, el papel de la FNC es clave para la economía de esta localidad no solo por su potencial para la generación de empleos directos, sino que, por su condición de tenencia de una buena cantidad de pasturas, está en la capacidad de brindar otro tipo de opciones laborales a la población. El régimen de tenencia, acceso y propiedad sobre la tierra que reposa sobre las áreas protegidas, es un factor que les implica un papel clave en las economías locales. Cuando los pobladores no tienen suficiente cantidad de tierras para sostener su economía, estas zonas de protección ambiental, por su extensión y riqueza en recursos naturales, pueden llegar a ser indispensables para la subsistencia local. Es allí donde un manejo y acceso participativo a los recursos de las áreas protegidas es fundamental para la vida de los habitantes locales. 
Una de las fuentes de tensión por el uso de la tierra a nivel local ocurre por la diferenciación que hace la FNC entre los procesos de "restauración ecológica", definidos por la Fundación como la siembra de especies nativas que cumplen con funciones dentro del ecosistema, a diferencia de la "reforestación", que significa la simple siembra sin ajustarse a los sistemas ecológicos (FNC, 2008b). La tensión consiste, específicamente, en que la siembra de otro tipo de especies que no se ajustan al ecosistema, como por ejemplo frutales, que es una propuesta de algunos habitantes, puede ser una opción de usos de la tierra que traería beneficios laborales a la población, pero sin concordar con los procesos de restauración ecológica.

Adicionalmente, algunos vecinos proponen el aprovechamiento de las tierras de la RBE en cultivos (los cuales dentro de la lógica local hacen parte de la naturaleza, véase capítulo I) que, acorde con el concepto de restauración ecológica, no cumplen con una función dentro de ese ecosistema alto andino, por lo que pueden no ser admitidos. Estas tensiones tienen como base el cambio de los usos mineros y agropecuarios por los usos conservacionistas y los beneficios que ciertos aprovechamientos pueden generar:

-Vecina: Claro que el beneficio que traía la mina, pues sí había harto trabajo, pero ahorita mismo ya no porque como, pues no dejan, no dejan sembrar cultivos de papa, no dejan nada, entonces solamente ehh la gente que llega [los turistas de la RBE] se dedican es a sembrar árboles. Y entonces lo de antes, lo del trabajo de la mina era sí mejor 
porque cultivaban papa y todo y ahorita mismo, pues no dejan cultivar papa, ni nada.

-Felipe Rojas: ¿O sea, quiénes no dejan, los de la Fundación?

-V: Sí, los de la Fundación. Yo creo, sí ellos. Ya no dejan, los de la reserva ya no dejan esos cultivos de papa, no dejan nada porque donde sembraban la papa eso todo están sembrando árboles. Solo árboles. (Entrevista a vecina del sector, 2 de septiembre de 2012)

Muchos de los pobladores locales identifican que uno de los principales usos que la FNC está haciendo de la tierra es la siembra de árboles. Dentro de las actividades que adelanta la FNC en la RBE, se encuentra el desarrollo de eventos recreativos con empresas privadas como caminatas por los senderos de la reserva, desayunos, almuerzos y fiestas de fin de año.

En casi todas estas actividades recreativas las empresas privadas compran a la FNC y siembran árboles bajo la orientación de los funcionarios de esta ONG. Así es que empresas privadas, Corpoguavio y algunas universidades tienen hectáreas de bosque sembradas en la RBE. Las entidades privadas y personas naturales tienen la posibilidad de deducir la inversión hecha en la hectárea sembrada (el costo es de 50.000 por hectárea anual para siembra y mantenimiento) y en su fiesta de fin de año o evento empresarial (realizado en la RBE) de su impuesto de renta en un $125 \%$ por compensación de huella de carbono e impacto ambiental, acorde con el artículo 12, de la Ley 663 de 2000 . Todo este trámite 
se hace por medio de un certificado de donación expedido por la FNC que las personas naturales y jurídicas presentan ante la Dirección de Impuestos para realizar la deducción.

Este tipo de prácticas hacen parte de la introducción de la naturaleza conservada en lógicas de mercado en donde los ecosistemas toman valor económico en sí mismos. En las lógicas ambientales del capital, la naturaleza y sus recursos han trascendido en bienes que para comercializarse, deben dejarse intactos. Los bonos de carbono y el ecoturismo son formas de consumo de la naturaleza construida como prístina.

Otra forma de producir este ambiente "natural" se encuentra en los procesos de restauración ecológica que propenden por restituir el bosque emulando y acelerando el "proceso natural” de reconstitución ecosistémica. Estos procesos en Guasca están atravesados por la economía de mercado, pues las empresas pagan por el desarrollo de la restauración, mitigación de cambio climático y huella de carbono, que, a su vez, generan ingresos a la FNC y financian el mantenimiento de la RBE. Estos procesos tienen que ver con nuevas formas de consumo y la extensión del mercado hacia nuevos bienes y servicios, en este caso relacionados con el cuidado ambiental.

Durante el desarrollo del trabajo de campo, se apreció que diversas empresas venían a la RBE y sus empleados sembraban árboles en su interior. También se constató la existencia de zonas de bosque sembradas bajo el patrocinio de empresas o actores privados (figura 8) que pagaron por su siembra y mantenimiento. Todo esto sugiere que el cuidado de la naturaleza es otra forma de extensión del mercado y 
una actividad descentrada de la acción pública, una forma neoliberal de proteger y producir la naturaleza. En esta lógica neoliberal, el bosque es producido como parcelas privadas que generan riqueza y por medio de las cuales las empresas cumplen requisitos de responsabilidad social empresarial.

Figura 8. Zonas restauradas bajo el patrocinio de actores privados, en este caso universidad que patrocina la siembra de árboles

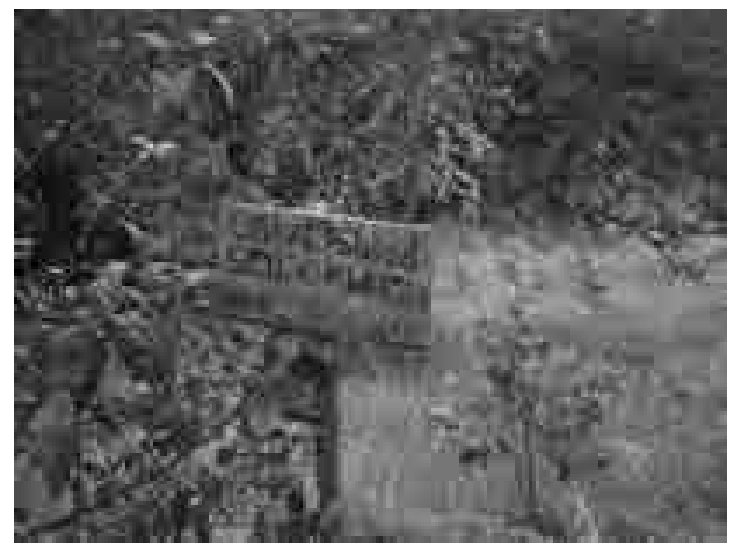

Fuente: Felipe Rojas, 2012.

En medio de un proceso denominado "gobernanza ambiental multitarea”, Agrawal y Lemos (2007) definen una forma de manejo ambiental que involucra al estado, las comunidades y el mercado. Este giro de un gobierno exclusivamente estatal a uno descentralizado tiene que ver con el neoliberalismo que implica que el estado ceda parte de sus funciones al sector privado. El caso de la RBE es un ejemplo claro al respecto. Gran parte de la financiación para el mantenimiento de la RBE proviene del mercado que compra 
servicios ambientales por compensación de huella de carbono, que a su vez son incentivados dentro de la política estatal a partir de la deducción fiscal. El estado "protege" al ambiente indirectamente a través de organizaciones privadas y el mercado. Por su parte, los vecinos de Pueblo Viejo son vinculados como compradores de servicios ambientales (pastos) en la RBE como otro mecanismo de financiación del área protegida. En este sentido, en una conversación el señor Hendrik Hoeck comentó que las áreas productivas de la RBE tienen como finalidad ser una fuente de financiación de la reserva a través de las concesiones de venta de pastos a los pobladores locales u otro tipo de actividades. Esta misma forma de financiación de la reserva la dio a conocer el jefe de la RBE en la entrevista que se le hizo.

Existen serias críticas a este modelo de manejo ambiental de la mano del mercado, muchas de las cuales versan sobre la privatización del ambiente y sus recursos. Este modelo se conoce como pago por servicios ambientales (PSA), cuya finalidad consiste en la compensación del daño a los ecosistemas por medio de contribuciones a programas de restauración ecológica y protección ambiental.

La sola mención de pago sugiere que los recursos naturales y sus "servicios" (palabra muy cuestionable por lo demás) son vendidos y comprados, es decir, tienen dueños. Algunos autores consideran estos mecanismos como formas de privatización del ambiente y sus funciones en el marco de la extensión del mercado (Bravo, 2012). Si bien muchas de las entidades que se encargan de proteger el ambiente (como la FNC) son sin ánimo de lucro, parte 
de los mecanismos por medio de los cuales cubren los altos costos de la conservación provienen del mercado. Por otro lado, se cuestiona que los PSA le ponen un precio a la naturaleza y desconocen los valores culturales, territoriales y simbólicos que esta tiene para las poblaciones locales (Bravo, 2012; Rojas, 2012).

En consecuencia, la economía de mercado ambiental irrumpe en los escenarios locales a través del conservacionismo y se convierte en una estrategia de financiamiento de los propósitos de la protección del entorno. La restauración ecológica debe entenderse entonces como una práctica económica y política global que genera cambios en los usos de los recursos ambientales a escala local, al asignar valores monetarios a la naturaleza prístina, y a las prácticas asociadas a su cuidado, y proponer conceptos ajenos a las formas locales de entender y usar la naturaleza como el de biodiversidad. Estos procesos de comercialización de bienes ambientales hacen de la naturaleza un elemento compatible con la rentabilidad y la acumulación del capital (O’Connor, 2003).

La siembra constante de árboles ha sido una fuente de preocupación entre algunos de los pobladores locales, pues saben lo que ello puede llegar a significar en cuanto a los potreros:

En el modo que siembran árboles, siembran y siembran árboles y entonces ya pues con el tiempo se forma como una montaña, como puede que sea un buen beneficio, sí, pero de todas maneras, donde eran buenos potreros, pues da como pesar. Sí, por unas partes es bueno ¿cierto?, pero 
entonces por unas partes ya se viene formando como mucho, mucha montaña [...]. (Entrevista a habitante local, 27 de agosto de 2012)

El hecho de que acaben los potreros implica que las personas que se están beneficiando por la venta de pastos que hace la FNC carezcan de sitios en donde pastar su ganado:

-Felipe Rojas: ¿Pero tal vez en un tiempo se vayan a acabar los potreros de pronto al ritmo que ellos están reforestando?

-Vecina: sí, al paso que van sí.

-FR: ¿Y ahí qué sucedería con, por ejemplo, con todas las personas que tienen ganado y les compran los pastos? -Vecina: ahí sí ya nos toca vender y buscar otra forma de trabajo. (Entrevista a habitante local, 8 de septiembre de 2012)

Otro vecino comentaba al respecto:

-Felipe Rojas: ¿Y qué pasaría si eventualmente esos potreros se terminaran, qué pasaría con la gente que está trabajando ahí actualmente pues con sus vaquitas?

-Vecino de Pueblo Viejo: Ah, no y ahí sí ya grave porque van sacándolos. Claro ya los van sacando, ya quedan ahí sin mantención, sin potreros de donde puedan mantener ni nada. Porque como eso es lo que quieren es hacer eso, de tener todo es pero solo bosque, bosque nativo. 
-FR: ¿Y considera usted que ese es de pronto el mejor uso que se le puede dar a esas tierras?

-VPV: Pues, por parte de estar, digamos de haber buenos bosques, buenos por evitar erosiones, por todas esas cosas, pues sí, serviría, pero por otras no porque de todas maneras la gente está quedando sin dónde mantener ni nada. Por decir por las aguas, pa' todo sí pues sirve, porque los bosques eso sirven de mucho, pero para la gente que tienen por ahí su ganado eso sí grave porque ya los van arrumando a sacarlos de una.

-FR: Y en cuanto a trabajo también porque...

-VPV: Pues de lógica porque si no tienen dónde mantener sus vacas, o algo, que muchos venden ahí sus diez, quince, veinte litricos de leche, pues ahí tienen para la mantención diaria. Y si se acaba eso, pues ahí quedan graves. (Entrevista a habitante local, 20 de agosto de 2012)

Uno de los principales problemas con el uso de los recursos en áreas protegidas consiste en la tensión constante entre conservación y subsistencia económica de la población local (Hernández et al., 2005). Los fragmentos de entrevista citados anteriormente expresan esta tensión, pues por una parte se ve con buenos ojos el que siembren, en tanto mejora las aguas y evita la erosión de los terrenos, pero, por el otro, puede que la restauración de todos los potreros afecte la economía de la mayoría de familias del sector que se dedican a la ganadería. Por otra parte, el problema por el uso de los recursos naturales tiene un matiz simbólico en las representaciones de la naturaleza como "monte” y "montaña”. 
El reparo sobre la siembra de árboles no consiste solamente en las dificultades económicas que acarrearía, sino en el crecimiento de una forma de naturaleza que no debe extenderse, "la montaña", como se analizó en el capítulo i. En algunos casos, esta tensión se ve expresada en la visión de algunos vecinos de la incompatibilidad de estos dos usos (ganaderos y conservacionistas) de la tierra:

Que donde siembren los árboles sí ya no se puede, por decir algo, sembrar pasto, tener ganado. Porque si se tiene ganado no se siembran árboles, cómo le digo yo, dos cosas no se pueden hacer porque el ganado daña los árboles o el ganado no come igual porque el pasto debajo de los árboles ya no va a producir igual. Para producir, para tener ganado hay que tener el potrero libre y para tener árboles hay que tener el potrero destinado para árboles. (Entrevista a poblador local, 3 de septiembre de 2012)

En otra entrevista comentaban:

Pero en cuanto a lo del ganadito, pues nos están quitando beneficios porque sembrando árboles no dejan meter ganado entre los árboles. Y entre más más, porque dicen que van a seguir sembrando más árboles, entonces ya, con el tiempo, pues ya. Por decir nosotros que tenemos, pues no es mucho ganado, pero ya nos toca venderlo porque no hay en dónde mantenerlos. (Entrevista a pobladora local, 6 de diciembre de 2012) 
Estas visiones contrastan con las apreciaciones del jefe de la reserva, quien asegura lo siguiente:

-Felipe Rojas: ¿Bueno y en ese sentido ustedes piensan restaurar todas las hectáreas de potreros que hay al interior? -Carlos Castillo: No. Digamos que en este momento es un tema como de discusión interna. Pero, digamos, la reserva como está planteada actualmente contempla la existencia de áreas productivas porque actualmente sostener una reserva es muy costoso y se requieren recursos y una fuente de recursos puede ser el uso sostenible de esas áreas productivas. Y no solamente un uso sostenible en función de la reserva, sino también en función de ser un referente a nivel regional. Es decir, si en la reserva empezamos a adoptar cierta cultura y ciertas prácticas de manejo del agua, de manejo del suelo, de manejo de la ganadería, de manejo de cultivos, podemos ser, de alguna manera, una vitrina, y un aula donde se pueda hacer esa pedagogía para beneficio de la región, pues porque conservar las doscientas áreas, las doscientas o 170 hectáreas o 150 hectáreas de bosque eso es insuficiente, eso es una miniatura. Lo que necesitamos es convocar a otros propietarios de la región para que adopten prácticas similares a las nuestras, para que en conjunto el efecto sea significativo. Pues doscientas hectáreas sí muy bonito y tal, pero pues digamos a escala del paisaje eso es un punto. (Entrevista a Carlos Castillo, jefe de la RBE, 18 de enero de 2013. Cursivas del autor) 
Tal como lo expone el jefe de la RBE, lo que se pretende es fomentar cierto tipo de usos de los recursos del entorno en la región. La adopción de nuevas formas de usufructo de los recursos naturales hace parte, según su interpretación, de un cambio cultural. Allí reposa un elemento clave de su forma de entender las maneras de relación de los seres humanos y su entorno, a saber, la mediación cultural, entendida como cierto de tipo de prácticas. En buena medida, se busca generar un cambio en las actividades de producción agropecuaria de la región en pro de la sostenibilidad. Estos cambios son fomentados por la educación de la población local frente al uso de los recursos naturales. En consecuencia, la intervención se hace por medio de la enseñanza, en este caso indirecta a través del ejemplo ("vitrina” y "aula”).

La existencia de “áreas productivas”, en opinión del jefe de la RBE, es una forma tanto de educación para la población local como de financiación de la reserva. Esto plantea una visión de las áreas protegidas no solo en cuanto a su impacto directo en la protección de las zonas delimitadas, sino en su convergencia con la producción en pro de beneficios económicos y una intervención indirecta sobre las formas de vida locales. Aquí entran en juego las disputas sobre las formas de determinar lo que se considera propio de un área protegida, así como lo adecuadas o inadecuadas de ciertas prácticas de usos de los recursos naturales. Las áreas protegidas intervienen el aprovechamiento del entorno, a la vez que fomentan indirecta o directamente ciertas formas de entender la naturaleza. 
La restauración de todos los potreros (que según el jefe de la RBE no sucederá) tendría repercusiones para las actividades ganaderas locales e, incluso, sobre la financiación de la RBE. Algunas de las apreciaciones de los vecinos al respecto citadas anteriormente parten del desconocimiento del plan de manejo de la RBE, pues no ha habido un diálogo formal y de concertación entre la FNC y la población local. Con todo, no deja de ser una fuente de preocupación teniendo en cuenta lo discutido en el capítulo in frente a las formas de trabajo que ofrece la FNC de manera directa a los pobladores locales.

Por el momento, ha sido fundamental que la FNC esté brindando la posibilidad a los habitantes de ejercer labores agropecuarias que les representan una fuente constante de ingresos que les permite vivir. Teniendo en cuenta este aspecto de la ganadería como opción laboral clave a partir de las concesiones en la RBE, se le preguntó al jefe de la reserva sobre la disminución de los potreros, las afectaciones que esto podría traer para la población y qué alternativas se podrían plantear para las familias:

-Felipe Rojas: ¿Y digamos ese número [de familias beneficiadas por la venta de pastos] puede fluctuar por los procesos de restauración o...?

-Carlos Castillo: Sí es posible que fluctúe, y digamos en eso también se ha hecho claridad ¿no? O sea que hay áreas que probablemente se van a disminuir por el proceso de restauración, pero hay otras que se van a conservar porque francamente su vocación es esa [ganadera] y si se les da un 
manejo adecuado pueden precisamente sostenerse, que a lo largo del tiempo puedan seguir siendo productivas. -FR: ¿Y se podrían plantear alternativas para esas familias de pronto que ya no pudieran seguir en el proceso de manejo productivo?

-CC: Yo sí creo que es importante, también hay que trabajar. O sea digamos lo que hay actualmente es un modelo de ganadería que tiene una tendencia más es hacia lo extensivo. De pronto se pueden reducir las áreas y dar manejos intensivos, pero sostenibles. Y se pueden también desarrollar otras actividades que no se están desarrollando, como por ejemplo producción o propagación de especies ornamentales, de orquídeas, de bromelias, agricultura orgánica, en fin. Cosas que no se están haciendo que se pueden hacer y que pueden generar otras alternativas de ingreso para los pobladores y si en algún momento hay una descompensación, digamos porque se reduce la oferta de áreas en concesión [venta de pastos], pues pueden por lo menos tener de dónde agarrarse. Va a depender de ellos el que lo hagan ¿no?, el que lo asimilen [...]. (Entrevista a Carlos Castillo, jefe de la RBE, 18 de enero de 2013)

A partir de esta cita, se puede deducir que, si bien todos los potreros no serán restaurados, la economía local puede verse afectada a partir de su reducción. Ante esta situación, habrá que ver cuáles medidas adoptará la FNC o cuál será su interés de contribuir al mejoramiento y la mitigación de estos problemas y cómo la población responderá ante estos cambios en sus prácticas productivas. 
Los cambios en el uso de los recursos ambientales podrán llegar a ser más profundos, pues, como lo expresa el jefe de la RBE, nuevas actividades económicas podrán darse en la vereda, como por ejemplo siembra de plantas ornamentales o agricultura orgánica. En este sentido, este estudio tiene como clave la localización de estas tensiones a partir de un conocimiento etnográfico. La perspectiva antropológica, entonces, es fundamental para dar cuenta de qué manera se dan en escenarios locales las luchas ambientales desde diversos matices. Una de las principales aristas que enfatiza el estudio antropológico de este tipo de tensiones es por cuenta de los significados:

-Felipe Rojas: ¿Pero entonces qué va a ser de las vaquitas cuando ya no haya potreros?

-Vecina: Por eso. Qué irán a hacer toda esa gente que tiene sus ganadito, qué irán hacer. Ahí otra miseria, otro terrible. Porque ya entonces ya ni un animalito ni nada. Eso es lo que se siente. Porque apenas ver ahí monte. Y ahí entonces principian a llegar las fieras, principia a llegar el oso, el león, el tigre. Y lo que dice en la sagrada biblia. No ve que dice que los últimos tiempos vendrán los animales, las fieras a poseer la casa de los justos. Y los justos irán a poseer la ca[sa], la madriguera de las fieras. En la sagrada biblia está. (Entrevista a pobladora local, 2 de septiembre de 2012)

Esta persona no solo habla de las carencias económicas que podría generar la siembra de árboles en todos los potreros, que por lo demás lo presenta de una manera sumamente 
desalentadora, sino que existen reparos simbólicos. Es interesante ver cómo esta vecina considera que al llenarse todo de "monte", los animales salvajes y peligrosos poblarían el lugar y serían una fuente de peligro para los vecinos. Este pensamiento está mediado por creencias apocalípticas del final de los tiempos. La forma de entender la naturaleza con sus propiedades de salvaje o peligrosa hace parte de una simbolización del entorno y sus usos.

Lo interesante de la anterior cita es que sugiere que los pobladores no solo tienen reparos en tanto sujetos económicos, sino que su capacidad de representar la naturaleza les permite interpelar las actividades desarrolladlas por la FNC, en particular los programas de restauración ecológica. Autores como González y Múnera (1998) plantean la necesidad de conocer las variables culturales que afectan e influyen en las formas de producción de los habitantes locales para el caso amazónico de la región de El Pato. Por su parte, Toledo y Barrera (2008) establecen una correlación entre cultura y prácticas productivas. Me parece interesante esta propuesta, pues da un papel relevante a aspectos culturales e históricos en el establecimiento de estrategias de diagnóstico de usos de los recursos del entorno y resolución de conflictos ambientales en comunidades campesinas. Esta propuesta analítica sugiere la relevancia del interés de la antropología por el estudio de las formas simbólicas de apropiación del ambiente en la determinación de planes de manejo ambiental. A continuación se dan a conocer algunas opiniones que dan cuenta de la apropiación simbólica de la naturaleza que repara la siembra de árboles en la RBE: 
Pasa como en el Caquetá. Sí. Eso es lo que se siente porque, porque qué tal que, que como en el Caquetá que allá se apoderó la guerrilla de todo esas montañas. Como la guerrilla tira es al monte, entonces claro que por aquí se va, se irá, Dios nos favorezca que se vaya a convertir en casa de la guerrilla. Porque esa gente tira es al monte. (Entrevista a pobladora local, 2 de septiembre de 2012). [...].

Pero lo malo es que ahorita todos los potreros los están sembrando en solo árboles y de pronto pues más inseguridad porque pues en todos esos árboles pueden haber robos o bueno, en fin, cosas. (Entrevista a pobladora local, 6 de diciembre de 2012)

Otro tipo de desacuerdos tienen que ver con elementos como el clima, debido a que algunos consideran que al sembrar más árboles, la temperatura del lugar se enfriaría aún más:

Uy, pero en esa parte sí me parece tenaz que siembren y siembren árboles porque es que el frío acá es tenaz. Y se imagina si siguen sembrando árboles, pues esto ya es un páramo. (Entrevista a vecina del sector 27 de agosto de 2012)

Estas opiniones sirven para superar el reduccionismo de pensar que los campesinos son solamente sujetos económicos, carentes de otras motivaciones para apropiarse de los espacios naturales en los que intervienen e interactúan, como por ejemplo las de tipo simbólico. Esto abre posibi- 
lidades para tener en cuenta cuáles son sus opiniones sobre el usufructo de los recursos naturales y las afectaciones que ello puede traer no solo en su economía, sino en su seguridad y salud.

Estas formas de pensar los árboles y su siembra en los potreros dan cuenta de la manera en la que se entiende el territorio y el entorno. La naturaleza es vista como un sitio salvaje, indómito y peligroso que puede traer peligros aunados al conflicto armado que vive el país o la delincuencia. Es interesante pensar cómo se diluyen los peligros humanos y los no humanos. La espesura del bosque tiene relación con peligros provenientes de sujetos como los ladrones o guerrilleros, lo que ayudaría a pensar en formas de representar a la naturaleza y a algunos humanos como intrínsecamente relacionados. Tal percepción permite dar cuenta de formas de trascender la división cultura-naturaleza. Ambas entidades se mezclan a la hora de pensar en la guerrilla o los ladrones que son como "especies salvajes" que habitan los bosques y selvas, al acecho para causar daños. El debate que plantea este tipo de opiniones se $\mathrm{da}$ frente a las formas en las que entendemos las necesidades de las poblaciones aledañas a las áreas de conservación. No se trata solamente de brindarles posibilidades económicas para su subsistencia, sino de articular la conservación con, y respetar, sus formas de entender el aprovechamiento de los recursos naturales y la relación con sus representaciones de la naturaleza.

Casos como el que presenta Durán (2009) para el Parque Nacional Natural Corales del Rosario y San Bernardo muestran cómo se desconocen las formas de usos de los recursos 
naturales y los conocimientos locales desde unas lógicas coloniales que ignoran y acusan a la población de ser la causante del deterioro ambiental. Esta tensión entre formas de vida, conocimientos locales y restricciones sobre el uso de recursos ambientales tiene un carácter global. Ha habido diversos casos en otras regiones y países en los que se han planteado una serie de alternativas que me parece pertinente traer a colación. Algunos versan sobre el desarrollo del ecoturismo teniendo en cuenta unas políticas de manejo que permitan la sostenibilidad de la población local y el ambiente a partir de esta actividad (Durán, 2009).

En la reserva faunística del Chimborazo, en Ecuador, se establecieron diálogos entre los conocimientos de la población local y los modelos ecoturísticos, se hicieron inventarios biológicos y se determinaron usos adecuados y no adecuados de los recursos naturales a partir de ello (Burbano, 2005). En otros casos, se han planteado propuestas interesantes de zonificación, un proceso que consiste en delimitar zonas aptas para el ejercicio de ciertas labores de conservación o producción como en el parque Los Alerces, en Argentina (Myers y Uribelarrea, 1992), o la Reserva Biosfera Maya, en Guatemala, en donde se propusieron áreas de usos múltiples y zonas de amortiguamiento para el aprovechamiento forestal de la población (Monterroso, 2006). Estos casos muestran que estas tensiones por el uso de los recursos naturales trascienden a Guasca y tienen un carácter global. Además, ponen en común propuestas que sirven para pensar planes de acción como la zonificación y el diálogo y la concertación con la población local, como herramientas 
clave para el manejo de áreas protegidas que se analizarán a continuación.

\section{Propuestas de los pobladores locales para el uso de la tierra, zonificación y articulación de usos "tradicionales" y usos de la conservación}

La valoración de los diversos tipos de conocimientos y propuestas de uso de los recursos naturales de los pobladores locales es una de las premisas del manejo ambiental comunitario y un punto de discusión dentro de la ecología política, que parte de los aportes de la antropología en el estudio de los saberes locales. Un artículo novedoso en su argumento sobre las formas de conocimiento ecológico tradicional (conocido como TEK, por su sigla en inglés), por su diferenciación de acuerdo al género y la edad, es el de Burbano (2005). Esta autora propone un diálogo de saberes locales y saberes de la conservación que permita conocer cuáles son las diferentes posiciones e intereses sobre los recursos naturales de diversos actores en el marco de la resolución de los conflictos ambientales. En particular, la autora propone un enfoque etario y de género, ya que considera que a partir de estos roles sociales surgen intereses y conocimientos diferenciados sobre los recursos naturales, muy relevantes a la hora de plantear el manejo de áreas protegidas.

Por su parte, autores como Wittmayer y Büscher (2010) y Tsing et al. (2005) discuten el modelo de manejo de recursos naturales basado en comunidades. Definen que uno de los pilares de este modelo es el reconocimiento de las tradiciones y los conocimientos locales frente a los recursos naturales y 
las complejidades de las prácticas y los procesos ecológicos, por lo menos en teoría. En este orden de ideas, dentro de la resolución de conflictos ambientales por el aprovechamiento de los recursos naturales, es pertinente fomentar un diálogo entre conocimientos locales y conocimientos de la conservación. En Pueblo Viejo ha faltado hasta el momento una discusión entre los administradores de la RBE y la población local en donde estos puntos se hagan visibles, pues aún están en formulación:

-Felipe Rojas: ¿Y de pronto en esos talleres que piensa implementar usted para este año, eh cabría la posibilidad de establecer por ejemplo cuáles son las propuestas que tendría la población frente al manejo de ciertos temas en la reserva, lo digo en el sentido de algunas propuestas, de algunos proyectos que ellos quieran manejar?

-Carlos Castillo: Claro, claro, claro. Digamos que son procesos abiertos, digamos que nosotros tenemos en mente algunas cosas y si ellos tienen otras ideas que pueden ser buenas, viables, son bienvenidas, digamos es un sistema abierto, no es un sistema impositivo. ¿Si?, ¿es hacia eso a donde iba tu pregunta?

-FR: Ajá. Digamos que hubiera como reuniones periódicas con la población, de pronto cada tanto tiempo donde se pudiera dialogar con ellos, con lo que usted decía de los que tienen las concesiones en la reserva con su ganado, que plantearan sus inquietudes frente a lo que están manejando y ustedes también de decirles “este manejo sí o no o cómo 
nos articulamos entre unos usos sostenibles, pero que pues garanticen la subsistencia local”.

-CC: Sí, esos espacios periódicos se van a dar, esos encuentros periódicos están dentro del plan de trabajo, por lo menos para este año y seguramente que esto habrá que extenderlo en el tiempo porque seguramente que van a ser procesos exitosos. La interacción con la comunidad es una cosa que va prevalecer en el tiempo. (Entrevista a Carlos Catillo, jefe de la RBE, 18 de enero de 2013)

Durante el trabajo de campo y las conversaciones con las personas, se pudo constatar que estos procesos de diálogo, en el sentido de participación e interacción para la construcción de propuestas entre la población y la FNC, no han tenido lugar hasta el momento. Con todo, el jefe de la reserva se muestra interesado en implementar una serie de talleres de educación ambiental, ${ }^{16}$ e incluso reuniones para la construcción de propuestas sobre el manejo de la RBE.

En lo que respecta al usufructo de los recursos del ambiente, en particular la tierra, la población local expone propuestas sobre su manejo al interior de la RBE que tienen que ver con sus conocimientos del entorno. En un modelo CBNRM la consulta con la comunidad, el reconocimiento del sufrimiento humano por cuenta de la conservación y del valor de las tradiciones comunales y sus formas de manejo

16 En el capítulo in se describió uno de los procesos que se dio - tal vez el único hasta el momento-de capacitación de la población local en temas ambientales en el proyecto de ecoguías. 
de los recursos naturales y el aumento (y negociación) de los derechos de las poblaciones rurales en términos de acceso e intercambio de los recursos son fundamentales, por lo menos en teoría (Wittmayer y Büscher, 2010).

En consonancia con lo anterior, algunos autores definen que el modelo CBNRM implica tres elementos: 1) permitir a aquellas poblaciones que habitan cerca de áreas protegidas la participación en las políticas del uso de la tierra y su manejo, 2) brindarles derechos de propiedad sobre los recursos naturales, y 3 ) otorgarles beneficios económicos a partir de la conservación ambiental (Hackle, 1999, p. 727, citado en Büscher y Dietz, 2005, p. 3).

El debate sobre el CBNRM es complejo (como se presentó en el capítulo I) e implica tener en cuenta que la base de este sistema es la pretensión, no necesariamente acertada, de que las comunidades están en la capacidad y tienen el interés de manejar sus tierras y recursos ambientales enfocados hacia la conservación ambiental y pretenden establecer reglas al respecto a través de un uso sustentable basado en la propiedad común (Roe et al., 2009; Tsing et al., 2005).

En ocasiones, esto no resulta estar acorde con las comunidades locales porque no necesariamente hacen usos "sustentables" de los recursos naturales, lo cual vulnera la sostenibilidad ambiental, pero también la subsistencia de las personas. Adicionalmente, se generan imposiciones de lo que es "sustentable" con base en intereses económicos, políticos y ambientales. No en vano este modelo es visto como una forma colonial de control, coerción y despojo sobre 
las poblaciones locales y sus recursos o de imposición de ciertos modelos y políticas de desarrollo (Tsing et al., 2005).

La declaración de lo que es o no sustentable no puede pensarse como una práctica neutra, sino enmarcada en relaciones de poder en donde se privilegian unos conocimientos y prácticas en detrimento de otros. Muchas de estas pretensiones están basadas en imaginarios occidentales sobre la naturaleza ecológica de las comunidades locales, en particular las indígenas. ${ }^{17}$ Las identidades encasilladas de los "nativos ecológicos" limitan los proyectos de vida de estas poblaciones que no necesariamente están alineados con la conservación o con imaginarios erróneos sobre su dependencia de los recursos (Li, 2002).

En la práctica del manejo de los recursos naturales, estas comunidades están subordinadas al estado, pues no son totalmente autónomas (a diferencia de lo que propone el modelo CBNRM a nivel conceptual), en tanto su derecho de manejo está sustentado en el poder que les trasfiere el estado (Roe et al., 2009).

Las comunidades no tienen el derecho de manejo por ser pobladores históricos del lugar y anteriores a la constitución de áreas protegidas, sino por cuenta del poder estatal o el que hace sus veces. El estado toma posesión de los recursos ambientales que pertenecen a las comunidades para luego otorgárselos por medio de concesiones de manejo, lo cual

17 Un texto interesante sobre la construcción de los indígenas como ecológicos es el de Astrid Ulloa (2004), titulado: La construcción del nativo ecológico: complejidades, paradojas y dilemas de la relación entre los movimientos indígenas y el ambientalismo en Colombia. 
es sumamente contradictorio. Esta situación imposibilita el real empoderamiento territorial de las poblaciones a través del modelo CBNRM. Además, este sistema crea comunidades imaginarias igualitarias desconociendo la heterogeneidad y diferencias de clase, género, etnicidad, edad, entre otras (Li, 2002; Wittmayer y Büscher, 2010). En buena medida, las críticas a este modelo parten del desfase que existe entre las teorías que lo sustentan y la realidad de las poblaciones cercanas a áreas protegidas. Tsing et al. (2005) critican este modelo por su aplicación descontextualizada, generalizante y deshistorizada.

$\mathrm{Li}$ (2002) sugiere que para que este sistema funcione, las reglas de conservación, manejo y asignación de los recursos naturales deben ser propuestas por la comunidad en cuestión, lo que supone una tensión con el modelo CBNRM, que propone que la conservación debe ser monitoreada por el estado. En este orden de ideas, es interesante analizar cuáles son las propuestas que presenta la población en cuanto al uso de la tierra en la RBE porque estas pueden contribuir a generar formas de participación efectivas en el manejo de la reserva. Las propuestas locales son fundamentales en la búsqueda de soluciones a los conflictos ambientales.

Más allá del modelo CBNRM que se viene discutiendo, es clave que en la RBE las poblaciones sean partícipes del manejo de esta no por imposición de actores externos, sino desde sus representaciones, necesidades e intereses de lo que debe ser la reserva. Partiendo de considerar la heterogeneidad de la población, sus saberes sobre el funcionamiento de la naturaleza, sus motivaciones e intereses frente a los beneficios y 
recursos naturales de la RBE, se puede llegar a construir un manejo más justo y democrático. Muestra de estos intereses, perspectivas y conocimientos locales son las diversas citas presentadas a lo largo de este texto. Aquí otra de ellas:

Porque es que acá en la reserva no tienen en cuenta una cosa, que los árboles se siembran es en las cabeceras, dónde está la tierra árida, digamos que para que coja humedad y lo están sembrando en cualquier lado, y digamos en los potreros aprovechables. Porque los árboles se deben sembrar es en las cabeceras de los potreros, donde hay esas lomas que no sale pasto, se siembra árboles y se abona la tierra se arregla y llama humedad. (Entrevista a poblador local dedicado a la ganadería, 3 de septiembre de 2012, cursivas del autor)

En la opinión de este poblador local saltan a la vista dos elementos. De un lado, denota una tensión por los conocimientos frente al uso que se le debe dar a la tierra. Su reparo versa sobre la siembra de árboles en ciertos lugares en donde no es debido hacerlo de acuerdo con su concepción, pues esto daña los potreros aprovechables para ganadería y agricultura. Este poblador expresa un conocimiento particular de la necesidad y las maneras de sembrar árboles en sitios determinados, debido a su vocación y características, lo que sugiere un segundo elemento: la zonificación. Este concepto, si bien no es acuñado directamente por el vecino, responde a la necesidad de sembrar árboles en los sitios menos aptos para pastoreo o sitios secos para su recuperación. La zonificación hace 
referencia a la delimitación y división de un área geográfica y las actividades en ella permitidas de acuerdo con la vocación de los suelos y los ecosistemas.

Acorde con ciertos modelos analíticos, un conflicto por el uso de la tierra se presenta en algunos casos cuando un aprovechamiento que no es apto para su vocación es practicado (González y Múnera, 1998), que es precisamente lo que sugiere, entre otras, la última cita textual presentada. En el caso de Guasca, el conflicto tiene esta característica, aunque en esta investigación se discrepa con el modelo analítico de los autores mencionados que establece solo criterios técnicos para determinar la vocación, pues, en mi opinión, los conocimientos locales no tecnificados sirven para determinar vocaciones y diagnosticar conflictos por el uso de los recursos ambientales.

La lógica del saber-poder presente en el argumento de González y Múnera otorga mayor legitimidad a los conocimientos técnicos ignorando otro tipo de saberes muy útiles y válidos para la determinación de la vocación de los suelos, como antesala a la zonificación. Los testimonios que se han citado dan cuenta de la existencia de conocimientos particulares que poseen los pobladores locales frente a las formas adecuadas de sembrar árboles y utilizar la tierra en la RBE, las cuales entran en tensión con los propuestos por la FNC.

González y Múnera (1998) asumen que los patrones culturales deben ser tenidos en cuenta para el diagnóstico de los modos de producción locales, en aras de su posterior modificación para mejorar las condiciones de conservación. Pero en el caso de la RBE, y de acuerdo con el fragmento de 
entrevista citado y la experiencia en campo, se considera que es necesario tener presente de qué manera estas poblaciones poseen unos conocimientos y unas experiencias particulares del medio que es necesario tener en cuenta para determinar la vocación del suelo, además de los criterios técnicos.

González y Múnera (1998) desconocen cuál ha sido la relación empírica de las poblaciones locales con el ambiente y su importancia para conocer el entorno y su vocación. En consecuencia, no se debe tener en cuenta los conocimientos locales solamente para su intervención, sino rescatar de ellos su aporte para el manejo de recursos naturales y establecimiento de zonas aptas y no aptas para el ejercicio de ciertas actividades en áreas protegidas. Esta idea de conocer la cultura para modificar prácticas productivas está también presente en las consideraciones del jefe de la RBE:

Claro, en la medida en que nosotros tenemos unas áreas productivas que estamos dando en concesión, pues digamos solicitamos a esos concesionarios que adopten, pues no de una manera impositiva, sino de una manera pues racional persuasiva, y ahí es donde entra el tema del cambio cultural. Cultura son las costumbres, costumbre de amarrar la vaca o soltarla o dejarla que haga lo que le dé la gana versus ¿no? manejar la cosa de otra manera. (Entrevista a Carlos Catillo, jefe de la RBE, 18 de enero de 2013

Esta visión de la cultura del jefe de la RBE contrasta profundamente con otro tipo de apreciaciones que abordan el asunto con mayor profundidad al dotar de sentido a las 
costumbres: "Entiendo por lógica cultural la estructura de sentido que subyace a las prácticas y estrategias campesinas, mediante las cuales hacen uso de los recursos y manejan las restricciones ecológicas y las dificultades económicas" (Cano, 2005 , p. 46, cursivas del autor). Lo interesante de este concepto es que adjudica a las costumbres y creencias culturales un papel importante en la configuración de sentido del mundo campesino, en tanto influyen en las formas productivas, de pensar el entorno y de aprovechamiento de sus recursos, lo cual contrarresta los análisis economicistas sobre las motivaciones campesinas y sus formas de apropiación del ambiente, como se discutió en el capítulo I.

El concepto de cultura es difuso y difícil de definir y encasillar, ${ }^{18}$ pero lo cierto es que no se trata solo de las costumbres, sino también de las creencias, el acervo cultural de conocimientos, las formas de representación, la experiencia empírica, las formas productivas, los mecanismos de socialización, entre otros aspectos. No hace parte únicamente del dominio de las prácticas y costumbres, sino de las estructuras de sentido, representaciones, trayectorias históricas, entre otros. La complejidad de este asunto es abordada por Toledo y Barrera (2008) al proponer intrincadas relaciones entre la cosmovisión y la cosmología de ciertos grupos humanos y sus formas de apropiación de los recursos naturales. Un cambio cultural va más allá de las prácticas, pues tiene relación con

18 Para una discusión de las diversas definiciones de cultura, su genealogía y trayectoria como concepto en la antropología, véanse Williams (2003) y Cuche (2007). 
unas formas de aprehensión y entendimiento del mundo decantadas por generaciones en la memoria individual y colectiva (Toledo y Barrera, 2008).

La indagación en terreno por la historia del poblamiento de Pueblo Viejo arrojó resultados interesantes frente a los conocimientos que pueden tener estos habitantes frente al medio circundante. Gran parte de las familias de este sector aseguran que sus padres y abuelos, y en algunos casos bisabuelos, son originarios de Pueblo Viejo. Algunas de las propiedades de estos habitantes son herencias familiares de sus padres y abuelos. Además, parte de las tierras posesión de la familia Hoeck pertenecieron a algunos de los ancestros de la población local, quienes la vendieron a esta familia. Según algunas de las escrituras del archivo de la Notaría del Circuito de Guatavita, la familia Hoeck hizo numerosas transacciones de predios con algunos de los familiares y ancestros de las actuales familias del lugar (Notaría del Circuito de Guatavita, 1943; 1945; 1946; 1947; 1948; 1949; 1958; 1966; 1970). Esta permanencia en el sector por varias generaciones sugiere que existe un conocimiento empírico y una prolongada interacción con el ambiente por parte de estos pobladores que pueden ser indispensables para la elaboración de los planes de manejo de la reserva, incluida la zonificación. ${ }^{19}$ Parte de este conocimiento se expresa en otras apreciaciones:

19 Toledo y Barrera (2008) abogan por la importancia del conocimiento empírico y mnemotécnico tradicional en la elaboración de planes de uso de los recursos en diálogo con el conocimiento técnico. 
Por decir algo, si yo tengo un lote, siembro árboles por la orilla de las quebradas, siembro árboles por la cabecera del potrero, pero nunca en la mitad, nunca eso. Porque hay potreros que no son aprovechables, lomas que por ejemplo allá uno dice allá no sale tanto pasto y qué rico que arboricen [...]. (Entrevista a poblador local dedicado a la ganadería, 3 de septiembre de 2012)

Una persona, a quien se le preguntó sobre la siembra de árboles, respondió lo siguiente:

Sí, así alrededor y qué dejarán, ¿ sabe qué decía yo?, así [que sembraran] alrededor y que dejaran los potreros libres, y podían vender, les salían más mejor vender los pastos. Sí, porque servían más, recibían la plata de los pastos que vendieran y así pa' los animalitos tenían ahí sus pastadas. (Entrevista a habitante local, 2 de septiembre de 2012)

Esta última persona comentó que le parecía que se debían sembrar los árboles en la RBE alrededor de los potreros y no en su interior, pues esto dañaba las fincas. En su manera de entender y conocer cómo se deben sembrar árboles en las fincas, salta a la vista una forma particular de usar la tierra que privilegia el cuidado de los potreros. Los conocimientos locales en Guasca se expresan en el saber frente a la vocación del suelo, la siembra de ciertas especies de árboles como alisos o eucaliptos y pinos como causa de la proliferación de fuentes hídricas o la erosión o daño de ciertos terrenos y la ausencia de agua, respectivamente. Otro tipo de conocimiento se expresa 
en las formas de contrarrestar temporadas secas acompañadas de heladas. En alguna ocasión, un vecino de Guasca explicaba que regando la huerta por la tarde con abundante agua se evitaba el daño causado por la helada durante la madrugada. Maneras de interpretar y hacer frente al clima, los conocimientos frente a la utilidad de ciertas plantas medicinales nativas tanto para humanos como para el ganado, así como comentaba una vecina de Guasca en alguna ocasión, son, entre otras, formas de conocimiento que tienen estas personas sobre el entorno.

Este conocimiento sobre el cuidado y uso de la tierra hace parte de unos saberes que entran en tensión con las formas de usufructo de los recursos ambientales en la RBE. Este tipo de opiniones arrojan luces sobre las propuestas de uso de la tierra que tiene la población para la RBE; usos y conocimientos que pueden ser tenidos en cuenta a la hora de formular planes de manejo y que empiezan a sugerir una zonificación de acuerdo con la vocación de los suelos que priorice cierto tipo de aprovechamientos. Para promover procesos de restauración del entorno, la estructura y función de los ecosistemas modificados, es necesario tener en cuenta los saberes de las poblaciones locales que conocen estos recursos y sus cambios a lo largo del tiempo (Cano, 2005). Así lo expresa una persona miembro de una familia dedicada a la ganadería:

Para ciertos terrenos [la siembra de árboles] fue la mejor opción. Porque, por decir algo, donde exploraban la piedra de cal ahí en eso fue una buena opción, exactamente. Porque es que digamos que le estamos envidiando a la reserva, no. 
Porque digamos la reserva tiene su derecho, como la tenemos todos, pero es que pa' ciertos terrenos tiene beneficio. Donde sacaron, donde estaban sacando esa piedra de cal, que se estaba erosionando, toda esa tierra se estaba abriendo, sembraron árboles, pues lógico que arreglaron y se va arreglar ahí y se va a volver esto a reforestar. Estamos hablando de los montes, de las lomas, de las cabeceras, pero en donde la están embarrando es en los potreros, digamos en los potreros aprovechables. (Entrevista a poblador local, 3 de septiembre de 2012)

Una persona, cuya familia se dedica a actividades pecuarias lo expresó así:

[...] como por ejemplo en partes donde son buenos potreros y eso no deberían de meter árboles [...]. Sí, eso por ejemplo deberían de seleccionar, cada, por ejemplo para las orillas, o nacederos del agua, sembrar lo que es por ejemplo aliso y eso que es lo que llama el agua, pero hay buenos potreros que ahí deberían dejar para pastoreo, pero con el tiempo yo creo que eso no, eso vienen acabando. (Entrevista a habitante de Pueblo Viejo, 27 de agosto de 2012, cursivas del autor)

Es interesante cómo las personas sugieren que el uso para siembra de árboles debe hacerse en zonas menos aptas para el pastoreo y con cierto tipo de especies, en especial en los bordes de los potreros, pues esta es una manera de articular los usos que propone la FNC en cuanto a ganadería y restauración ecológica. Sugieren, además, lo poco apto que resulta el 
desarrollo de la actividad minera y la importancia de sembrar para recuperar el daño de la explotación. Muchos proponen que sí es benéfico que se siembre la especie aliso (Alnus acuminata) en ciertas zonas, pues, según su conocimiento ecológico "tradicional", es una especie que fortalece la humedad y proliferación de fuentes hídricas.

Durante la entrevista, una persona expresaba estar de acuerdo con la forma en que la FNC estaba usando las tierras en actividades mixtas: ganadería y restauración ecológica. Para ella, la FNC estaba haciendo un adecuado uso de la tierra en tanto permitía la ganadería en zonas aptas para su ejercicio, mientras que restauraba (reforestaba en sus términos) las partes que producían menos pasto. Detrás de estas opiniones existe una lógica de zonificar de acuerdo con la vocación y productividad de los suelos de la RBE. Este tema ha sido objeto de trabajo y discusión dentro de los planes de manejo en diferentes áreas protegidas alrededor del mundo. En Colombia, existen casos como el de La Macarena en donde, mediante el Decreto 1989 del 1 de septiembre de 1989, se crea el Área Especial de Manejo de La Macarena, con el fin de buscar el bienestar social y ambiental, además del establecimiento de una zonificación interna de acuerdo con el potencial y deterioro de los suelos en el Parque Nacional Natural ubicado en esta región (Castaño, 1992). En el Parque Nacional Sierra Nevada en Venezuela se planteó una zonificación para promover o excluir ciertos usos de acuerdo con las características de cada área, en el marco de un diálogo con la población, que reconoció los valores y las prácticas tradicionales de las culturas campesinas (Reyes y López, 1992). 
Estos casos muestran algunas de las tendencias de manejo de áreas protegidas de la mano de las poblaciones. Son un marco de referencia de posibles planes de acción que aún no han sido propuestos en la RBE y que enfatizan en la zonificación concertada como salida viable a conflictos por el uso de los recursos naturales. Asimismo, estos casos muestran cómo las tensiones por el uso de la tierra en la RBE no se encuentran aisladas, sino que hacen parte de procesos globales de cuidado y manejo ambiental que implican tensiones y negociación entre las partes involucradas.

La zonificación es solo una de las propuestas para el manejo de las áreas protegidas. Existen otro tipo de iniciativas que, de la mano de la zonificación, pueden fomentar la disminución de los conflictos por el aprovechamiento de los recursos naturales entre administradores de áreas protegidas y la población local, así como promover tanto la conservación como la subsistencia. El diálogo y la concertación son algunas de las actividades sugeridas en diversos casos que permiten que la población se haga partícipe en los planes de manejo de las áreas protegidas y protección ambiental en aras de resolver conflictos por el uso de recursos, el deterioro ambiental y el desarrollo local (Del Cairo, 2010; Osidala, et al., 1992; Durán, 2009; Londoño, 2008). Esta propuesta se debe hacer de la mano de los conocimientos locales sobre la aptitud y vocación de los suelos. Con todo, las discrepancias por el uso de los recursos ambientales son de parte y parte:

-Felipe Rojas: ¿O sea que ustedes creen que algunos de los usos que están dando, que están ejerciendo los pobladores 
locales no son sostenibles, qué usos serían esos o en qué hay que mejorar en ese sentido?

-Carlos Castillo: Sí, claro que hay mucho en el manejo del recurso hídrico, por ejemplo, digamos no hay una cultura de ahorro porque, entre otras cosas, es una zona rica en fuentes hídricas, pero si vemos, si hubieras ido en estos días en que hubo sequía ya la gente estaba [gesto de preocupación], pero es porque no ahorran. Desperdician agua todo el año. "Sí que qué invierno y qué cosa y qué llovedera y”, pero si no se ahorra el recurso, entonces hay esos desequilibrios.

-FR: ¿Y en las actividades pecuarias, habría...?

-CC: También. Hay muchos temas en la actividad pecuaria que pueden mejorarse en una lógica de sostenibilidad. Como en las praderas, el manejo y control de plagas, digamos que las mismas coberturas de pastos y todo eso hay muchísimos aspectos en que pueden mejorar su productividad y la sostenibilidad, esos indicadores en ambos sentidos. (Entrevista a Carlos Castillo, jefe de la RBE, 18 de enero de 2013)

En Pueblo Viejo existen desacuerdos por el uso de la tierra entre la población local y la FNC. Si bien hay puntos en los que ambas partes concuerdan, en especial en cuanto a la importancia de sembrar árboles para recuperar el daño ambiental causado por la mina o incrementar las fuentes hídricas, los habitantes consideran que la FNC está mal utilizando algunas zonas al sembrar árboles en los potreros que pueden llegar a tener una vocación productiva. 
A futuro, consideran muchos, los potreros al interior de la RBE van a escasear en su totalidad, lo que los obligará a vender su ganado y buscar otro tipo de actividad económica. Sin embargo, esta opinión parte del desconocimiento y la falta de diálogo entre estos dos actores, pues, así como lo expresa el jefe de la reserva, no todos los potreros van a ser restaurados. En suma, los conflictos por los usos de la tierra se relacionan con las consideraciones que tienen los diversos actores sobre la capacidad de los suelos, los conocimientos ambientales, las relaciones entre el saber y el poder, la representación de la naturaleza y las actividades económicas.

En este capítulo se sugiere la necesidad de contextualizar los conflictos de los recursos naturales en el marco de las relaciones desiguales de poder que, en este caso, parten del régimen de propiedad privada que pesa sobre la reserva y la posición que ocupó por muchos años la familia Hoeck como empleador y arrendador de la población local. Estas dos características hacen que la FNC sea la que tenga la capacidad de proponer lo usos de la tierra al interior de la RBE. Por otro lado, estos conflictos y tensiones deben entenderse como procesos en los cuales los sujetos no asumen de manera pasiva los usos, sino que tienen la capacidad de oponerse o acogerse a estos. Los sujetos toman posiciones frente a los aprovechamientos de la tierra de acuerdo con el lugar que ocupan en la jerarquía social, sus actividades económicas, sus aspiraciones de vida e incluso sus formas de representar la naturaleza y sus saberes. 
Esto implica no considerar a las comunidades como homogéneas, sino entender sus diversas formas de usar y conocer los recursos ambientales de acuerdo con sus roles sociales (Burbano, 2005). El diálogo y la concertación son algunas de las herramientas útiles para solucionar estos conflictos, toda vez que las partes se conozcan y entienden sus motivaciones para tomar ciertas posiciones con respecto al uso de los recursos naturales.

La restricción y el cambio sobre los aprovechamientos de los recursos naturales que trae consigo un área protegida son motivos constantes de disputa y negociación entre las distintas partes involucradas. La tensión es mayor en tanto los usos introducidos por la conservación en la RBE son ajenos a muchas de las experiencias y conocimientos locales.

Para algunos de los vecinos de esta área protegida, era un tanto difícil comprender por qué se sembraban tantos árboles en los potreros, en especial en aquellos que por sus características (según las versiones de los pobladores) podrían ser utilizados para actividades agropecuarias. Además de lo económico, muchos habitantes consideran que el uso en la siembra de árboles puede traer consecuencias para la salud y seguridad local. 